\title{
Prolidase deficiency and systemic lupus erythematosus
}

\author{
M Shrinath, J H Walter, M Haeney, J M Couriel, M A Lewis, A L Herrick
}

Royal Manchester Children's Hospital, Manchester: Willink Biochemical Genetics Unit M Shrinath

J H Walter

Department of Nephrology

M A Lewis

Booth Hall Children's Hospital, Manchester J M Couriel

Hope Hospital, Salford:

Department of Immunology

M Haeney

Department of Rheumatology A L Herrick

Correspondence to: Dr J H Walter, Willink Biochemical Genetics Unit, Royal Manchester Children's Hospital, Manchester M27 5ER.

Accepted 31 January 1997

\begin{abstract}
Two children with prolidase deficiency, an inborn error of proline metabolism, developed clinical and immunological abnormalities consistent with a diagnosis of systemic lupus erythematosus (SLE). The first child died from septicaemia, and SLE was only diagnosed during his terminal illness. As a result of this diagnosis his cousin, who was already known to have prolidase deficiency, was investigated further and a diagnosis of SLE confirmed. Following treatment with oral prednisolone her clinical condition has improved, although she has a persistently raised erythrocyte sedimentation rate (ESR) and florid facial rash. Both prolidase deficiency and SLE are associated with disturbances in immune function and have clinical features in common. It is likely that prolidase deficiency is a risk factor for the development of SLE. Additionally, patients with SLE should-where there is a family history or presentation in childhood-be specifically investigated for prolidase deficiency, since standard immunological or haematological investigations will not identify the characteristic biochemical abnormalities.

(Arch Dis Child 1997;76:441-444)
\end{abstract}

Keywords: prolidase deficiency; systemic lupus erythematosus

Prolidase deficiency is a rare autosomal recessive disorder, first described in $1968 .^{1}$ Symptoms are highly variable but include rashes or skin ulceration, dysmorphic features, cognitive impairment, anaemia, splenomegaly, and recurrent infections. ${ }^{2}$ Prolidase splits dipeptides containing C-terminal proline or hydroxyproline. In prolidase deficiency, normal recycling of proline cannot occur, and this leads to iminopeptiduria, the characteristic biochemical abnormality. Diagnosis can be confirmed by enzyme assay on leucocytes, erythrocytes, or cultured fibroblasts. $^{2}$

Immunological abnormalities are common in prolidase deficiency. In 1994 we reported impaired immune function in two patients with prolidase deficiency. ${ }^{3}$ These children were found to have high serum concentrations of immunoglobulins, consistent with recurrent infections and abnormal neutrophil chemotaxis. Recently, a patient with systemic lupus erythematosus (SLE) was also found to be suffering from prolidase deficiency, although it was not clear whether the two disorders were associated. ${ }^{4}$ We now report the development of clinical and immunological features compatible with a diagnosis of SLE in two further patients with prolidase deficiency.

\section{Case reports}

PATIENT 1

Patient 1, a male child, was the second of four children born to parents, originally from Pakistan, who are first cousins (fig 1). His youngest sibling, a girl, had died at the age of 3 months following surgery for bowel malrotation, and was also found to have prolidase deficiency, but had no immunological investigations before her death. His other two siblings, both boys, are well. Patient 1 was born by normal vaginal delivery at term with a birth weight of $2330 \mathrm{~g}$. From the age of 3 weeks he suffered from recurrent and protracted diarrhoea. He subsequently developed failure to thrive, progressive hepatosplenomegaly, and recurrent infections. A diagnosis of prolidase deficiency was made at the age of 9 months on the basis of iminopeptiduria and this was later confirmed by finding deficient prolidase activity in skin fibroblasts (table 1). Frequent gastrointestinal and chest infections occurred in the next two years along with iron deficiency anaemia and a nonspecific maculopapular rash. Subsequently, moderate learning difficulties and facial dysmorphism were apparent and the rash became localised primarily to the face in a butterfly distribution. Between 4 and 7 years of age the frequency of his infections became less. Joint swellings and mouth ulcers were noted on one occasion. Repeated episodes of bacterial pneumonia involving the right lung, leading to persistent $x$ ray changes, were the main problem after the age of 7 . Immunological investigations revealed increased IgG and IgA concentrations (table 2) with classical pathway complement consumption and abnormal neutrophil chemotaxis. ${ }^{3}$ At the age of 8 years he was admitted to hospital with abdominal pain and subsequently developed a facial abscess and septicaemia (requiring ventilatory support), a vasculitic rash, thrombocytopenia, neutropenia, proteinuria, pericarditis, and ankle and elbow swelling. A diagnosis of SLE was made on the basis of strongly positive double stranded (ds) DNA antibodies and positive ANF (table 2) and clinical features meeting the diagnostic criteria of the American Rheumatism Association (table 3). ${ }^{5}$ Despite intensive care, plasmapheresis, and high dose steroids, he died four weeks later. 
Table 1 Fibroblast prolidase activities (expressed as $m m o l / h$ per $m g$ protein) in patient 1

\begin{tabular}{|c|c|c|c|c|}
\hline & \multicolumn{4}{|l|}{ Substrate } \\
\hline & $\begin{array}{l}\text { Leucyl-proline } \\
-\mathrm{Mn}^{2+}\end{array}$ & $+M n^{2+}$ & $\begin{array}{l}\text { Glycyl-proline } \\
-\mathrm{Mn}^{2+}\end{array}$ & $+M n^{2+}$ \\
\hline Patient 1 & 0.037 & 0.73 & 0.037 & 0.17 \\
\hline Controls, $\mathrm{n}=6$ (SEM) & $2.78(0.79)$ & $3.80(0.90)$ & $0.98(0.32)$ & $6.94(0.64)$ \\
\hline
\end{tabular}

$-\mathrm{Mn}^{2+}=$ in the absence of $1 \mathrm{mmol} / 1 \mathrm{MnSO}_{4} ;+\mathrm{Mn}^{2+}=$ in the presence of $1 \mathrm{mmol} / 1 \mathrm{MnSO}_{4}$.

PATIENT 2

Patient 2, a 5 year old female child, is the first cousin to patient 1 . Her parents are first cousins and are the brother and sister of patient 1's parents (fig 1). She was born at term by normal vaginal delivery, weighing $2600 \mathrm{~g}$. In view of her cousin's illness she was investigated for prolidase deficiency in infancy. The diagnosis was established at the age of 6 months on the basis of urine amino acid chromatography and amino acid analysis of hydrolysed plasma supernatant, which showed large amounts of iminoacids. At the time of diagnosis, her growth and development were age appropriate. Soon after her first birthday she developed recurrent otitis media and abscesses of her face and neck and chronic diarrhoea. On investigation, she was found to have markedly raised immunoglobulin concentrations and abnormal neutrophil chemotaxis. ${ }^{3}$ In the third year of life she suffered from a recurrent pyrexial illness associated with pneumonia, recurrent mouth ulcers, neutropenia, and thrombocytopenia. She developed a florid facial rash with a butterfly distribution. A positive Coombs test was noted but bone marrow findings were nonspecific. A diagnosis of SLE was made on the basis of the results of further immunological investigations (table 2) and her clinical findings which fulfilled the diagnostic criteria of the American Rheumatism Association (table 3). ${ }^{5}$
Following treatment with oral prednisolone she made good progress. At the time of writing, she had had no further infections, her ESRalthough still raised-had fallen significantly, and her white cell count was within normal limits. However, her facial rash persisted.

\section{Methods}

Urinary amino acids were routinely studied by two dimensional thin layer chromatography and stained with ninhydrin. The imidodipeptides glycylproline and leucylproline, excreted in excessive amounts in these patients, were identified by column chromatography with authentic standards. The major urinary dipeptide, glycylproline, characteristically stained bright yellow initially and then turned purple and on acid hydrolysis gave rise to glycine and proline. Both patients showed these characteristics.

Prolidase activity was measured on cultured skin fibroblasts basically as described by Myara et $a l^{6}$ using leucylproline and glycylproline as substrates and measuring the liberated proline spectrophotometrically with Chinard's reagent.

Serum immunoglobulin and complement C3 and C4 concentrations were measured by rate nephelometry using a Beckman Array '360' System. Functional activity of the classi-

Table 2 Immunological results-patients 1 and 2

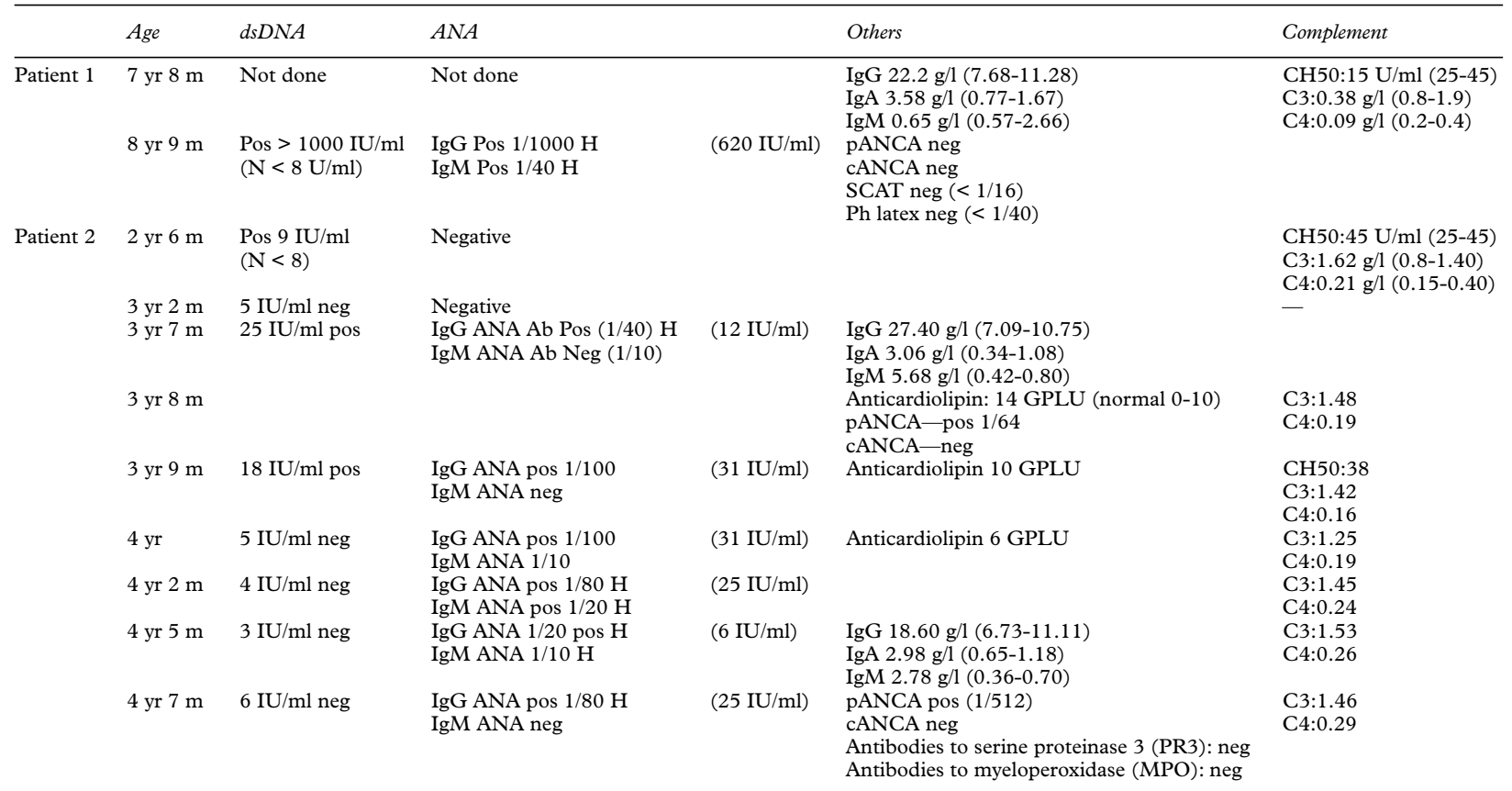

$\mathrm{N}=$ normal; $\mathrm{H}=$ homogeneous; dsDNA = double stranded DNA; ANA = antinuclear antibodies; pANCA = perinuclear antineutrophil cytoplasmic antibody; cANCA = classical anti-neutrophil cytoplasmic antibody; GPLU = IgG phospholipid units. 
Table 3 The 1982 criteria for the classification of SLE. A diagnosis of SLE can be made with 98\% specificity and 97\% sensitivity if four of the criteria listed below are present at any time

\begin{tabular}{|c|c|c|}
\hline Diagnostic criteria of the American Rheumatism Association & Patient 1 & Patient 2 \\
\hline Malar rash & - & Yes \\
\hline Discoid rash & - & - \\
\hline Photosensitivity & - & \\
\hline Oral ulcers & - & Yes \\
\hline Arthritis (non-erosive arthritis involving two or more peripheral joints, characterised by & & \\
\hline tenderness, swelling, or effusion) & Yes & - \\
\hline Serositis (pleuritis or pericarditis) & Yes & - \\
\hline Renal disorder (proteinuria $>5.0 \mathrm{~g} / \mathrm{dl}$ or $3+$ protein, or cellular casts) & Yes & - \\
\hline Neurological disorder & - & - \\
\hline $\begin{array}{l}\text { Haematological disorder (haemolytic anaemia, leukopenia, lymphopenia, or } \\
\text { thrombocytopenia) }\end{array}$ & Yes & Yes \\
\hline $\begin{array}{l}\text { Immunological disorder (positive LE cell preparation or anti-dsDNA or anti-Sm } \\
\text { antibodies or false positive VDRL) }\end{array}$ & Yes & Yes \\
\hline Antinuclear antibodies & Yes & Yes \\
\hline
\end{tabular}

cal complement pathway ( $\mathrm{CH} 50)$ was measured by haemolysis of erythrocytes sensitised with optimal amounts of antierythrocyte antibody. ${ }^{7}$

Antinuclear antibodies were detected by indirect immunofluorescence using Hep-2 cells as substrate and dsDNA antibodies were measured by radioimmunoassay (Life Screen, Watford). Antineutrophil cytoplasmic antibodies (pANCA) were detected by indirect immunofluorescence as described by Wiik. ${ }^{8}$ Positive sera were tested for reactivity against serine proteinase 3 or myeloperoxidase using an enzyme linked immunosorbent assay (ELISA) system.

\section{Results}

Fibroblast prolidase activity was markedly reduced in patient 1 (table 1 ) but not studied in patient 2 . The results of the immunological investigations for patients 1 and 2 are listed in table 2. Both patients have had raised DNA and positive antinuclear antibodies. In addition, patient 2 has a significantly positive pANCA and borderline anticardiolipin antibody. These results, combined with their clinical findings, fulfil the diagnostic criteria for SLE (table 3).

\section{Discussion}

Prolidase deficiency is a rare inborn error of metabolism with only about 30 patients reported. ${ }^{2-4}$ Prolidase acts by cleaving dipeptides with a C-terminal proline or hydroxyproline. Proline is recycled and is used in further protein synthesis, while hydroxyproline is excreted in the urine. In prolidase deficiency, a

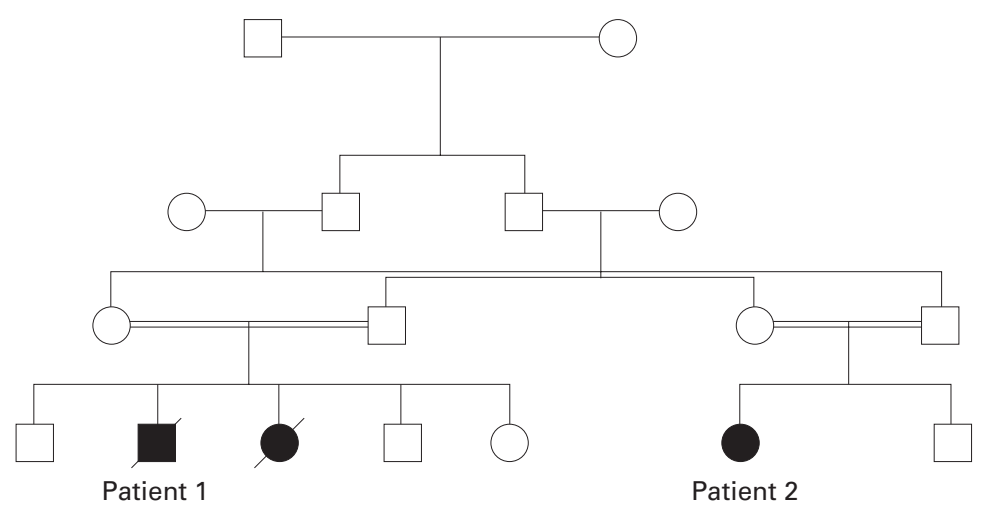

Figure 1 Family pedigree. large amount of proline bound to iminopeptides, such as glycylproline, is excreted in urine and this results in depletion of the total body pool of proline. Iminopeptiduria also occurs in conditions such as rickets, Paget's disease, and hyperparathyroidism, but the degree of iminopeptiduria is much less than in prolidase deficiency. Human prolidase is a dimer of identical subunits, each of 492 amino acid residues. The gene for prolidase is localised on chromosome 19, spanning more than $130 \times 10^{3}$ base pairs. ${ }^{9}$ Prolidase deficiency is a multisystem disorder in which skin ulceration is the most prominent finding. Other common features include characteristic facies, mental retardation, splenomegaly, and susceptibility to infections. ${ }^{3}$ Skin ulcers are usually long standing and difficult to heal. Scarring and pitting are common. Eczematous lesions, telangiectasia, and purpura are other dermatological features. Pruritus, photosensitivity, and hyperkeratosis have also been described. ${ }^{10}$ Other reported clinical findings include a high arched palate, simian creases, wasting of the small muscles of the hand, joint laxity, short stature, osteoporosis, talipes equinovarus, deafness, and ocular keratitis. Attempts have been made to elucidate the pathological expression of biochemical defects in prolidase deficiency by various workers. Changes in the blood vessels in the form of hyalinisation and thickening have been reported, along with thrombus formation in small vessels and capillaries. Magnetic resonance imaging (MRI) of the brain has shown multiple microthrombi in cerebral white matter. ${ }^{11}$ Ultrastructurally, collagen molecules have been found to be shortened and to show non-homogeneous packing of fibrils. ${ }^{12}$ It appears, therefore, that the pathogenesis involves angiopathy of small blood vessels, probably due to disturbance of connective tissue metabolism by deficiency of the enzyme prolidase. Mental retardation and the MRI changes described also appear to be related to angiopathy.

An association between systemic lupus erythematosus and prolidase deficiency has been reported only once previously. ${ }^{4}$ A 16 year old girl was diagnosed as having SLE on the basis of clinical features including nephritis and presence of antinuclear antibodies. She developed chronic non-healing skin ulceration, and on further investigation was found to have prolidase deficiency. Both our patients were known to have prolidase deficiency and immunodefi- 
ciency before their diagnosis of SLE. Immunological abnormalities consistent with SLE only developed later in the course of their illness. Our patients did not have overt neurological involvement. However, both had a malar rash and oral ulceration. In addition, patient 1 had evidence of renal disease, serositis, and arthritis while patient 2 showed typical haematological features of SLE, namely haemolysis, neutropenia, and thrombocytopenia. Both fulfilled the diagnostic criteria for SLE of the American Rheumatism Association. ${ }^{5}$ Chronic lung disease with $x$ ray changes was a major feature in patient 1. This was thought to be due to immunodeficiency associated with prolidase deficiency but could have been SLE related in view of the common involvement of the respiratory tract in this condition. ${ }^{13}$

SLE is a much more common disorder than prolidase deficiency, with a prevalence in the United Kingdom and the USA of about 30 in 100000 people, although the true figure may be higher. ${ }^{14}$ It is less prevalent in children than in adults, and patients with onset in childhood more often have a malar rash and nephropathy as presenting features. ${ }^{15}$ Delay in diagnosis in this group is common, with a reported mean delay of five years. ${ }^{15}$ There is some overlap of clinical features between SLE and prolidase deficiency, which is perhaps not surprising since both are multisystem disorders in which vasculopathy appears to be a significant factor in the pathogenesis. Both conditions are associated with immunological dysfunction. Production of autoantibodies to cellular macromolecules is the central immunological disturbance in SLE. Such autoantibodies may be pathogenic, causing tissue injury by an immune complex mediated inflammatory response or by autoantibody mediated cellular dysfunction. The autoimmune response is believed to result from the interactions of genetic and environmental factors. ${ }^{16}$ The underlying disturbance in the immune system in prolidase deficiency is not known. Raised immunoglobulins are probably secondary to recurrent infections, and it is not clear whether the reduced neutrophil chemotaxis found in our patients was a primary or a secondary phenomenon.

In lupus-prone mice, genetic factors exert important influences on the predisposition to SLE. Major histocompatibility complex, immunoglobulin, and $\mathrm{T}$ cell receptor genes appear to be involved in influencing disease susceptibility. The role of genetic factors is less clear in humans. Concordance for SLE in monozygotic twins identified through a twin registry was only $30 \%$, compared with $5 \%$ in dizygotic twins. ${ }^{16}$ While genetic influences are clearly important, the lack of $100 \%$ concordance in monozygotic twins implies that non- germline factors, such as environmental influences, are important for the development of the disease on any particular genetic background. Although an association with certain HLA groups is well recognised, a candidate 'autoimmunity gene' has not yet been identified. The association of prolidase deficiency with SLE suggests that the prolidase deficiency gene on chromosome 19 may influence the autoimmunity gene, or genes, of SLE.

In conclusion, there appears to be an association between prolidase deficiency and SLE. This finding may be important in furthering our understanding of the aetiology of SLE. Furthermore, since iminopeptiduria is not identified using standard laboratory investigations, it is possible that some patients with SLE-particularly where there is a family history or onset in childhood-also have prolidase deficiency. We suggest that all such patients have urine amino acid analysis and that patients with prolidase deficiency are investigated for SLE.

1 Goodman SI, Solomons CC, Muschenheim F, McIntyre CA, Miles B, O'Brien D. A syndrome resembling lathyrism. Am f Med 1968;45:152-9.

2 Phang JM, Yeh GC, Scriver CR. Disorders of proline and hydroxyproline metabolism. In: Scriver CR, Beaudet AL, Sly WS, Valle D, eds. The metabolic and molecular basis of inherited disease, 7th ed. New York: McGraw Hill,

3 Cleary MA, Haeney M, Couriel JM, Walter JH. Immune function in prolidase deficiency. F Inherit Metab Dis

4 Bissonnette R, Friedmann D, Giroux JM, et al. Prolidase deficiency: a multisystemic hereditary disorder. $\mathcal{F}$ Am Acad Dermatol 1993;29:818-21.

5 Tan EM, Cohen AS, Fries JF, et al. The 1982 revised criteria for the classification of systemic lupus erythematosus. Arthritis Rheum 1982;25:1271-7.

6 Myara I, Charpentier C, Lemonnier A. Optimal conditions for prolidase assay by proline colorimetric determination: application to iminodipeptiduria. Clin Chim Acta 1982;125: 193-205.

7 Gooi HC, Chapel HM. Clinical immunology. A practical approach. Oxford: IRL Press, 1990.

8 Wiik A. Delineation of a standard procedure for indirect immunofluorescence detection of ANCA. APMIS Suppl 1989;6:12-13.

9 Endo F, Matsuda I. Molecular basis of prolidase (peptidase D) deficiency. Mol Biol Med 1991;8:117-27.

10 Milligan A, Graham Brown RA, Burns DA, Anderson I. Milligan A, Graham Brown RA, Burns DA, Anderson I.
Prolidase deficiency: a case report and literature review. $B r$ frolidase deficiency: a case $\mathrm{rep}$

11 Arata J, Tada J, Yamada T, Oono T, Yasutomi H, Oka E. Angiopathic pathogenesis of clinical manifestations in prolidase deficiency [letter]. Arch Dermatol 1991;127:124-5.

12 Leoni A, Cetta G, Tenni R, et al. Prolidase deficiency in two siblings with chronic leg ulcerations. Clinical, biochemical, and morphologic aspects. Arch Dermatol 1987;123:493-9.

13 Boumpas DT, Austin HA, Fessler BJ, Balow JE, Klippel JH, Lockshin MD. Systemic lupus erythematosus: emerging concepts. Part 1: Renal, neuropsychiatric, cardiovascular, pulmonary, and hematologic disease. Ann Intern Med 1995;122:940-50.

14 Johnson AE, Gordon C, Hobbs FDR, Bacon PA. Undiagnosed systemic lupus erythematosus in the country. Lancet 1996;347:367-9.

15 Cervera R, Khamashta MA, Font J, et al. Systemic lupus erythematosus: clinical and immunologic patterns of disease expression in a cohort of 1,000 patients. The European Working Party on Systemic Lupus Erythematosus. pean Working Party on Systemic
Medicine Baltimore 1993;72:113-24

16 Boumpas DT, Fessler BJ, Austin HA, Balow JE, Klippel JH, Lockshin MD. Systemic lupus erythematosus: emerging concepts. Part 2: Dermatologic and joint disease, the antiphospholipid antibody syndrome, pregnancy and hormonal therapy, morbidity and mortality, and pathogenesis. Ann Intern Med 1995;123:42-53. 